Transluminal laser angioplasty に関する実鈳的研究

\author{
Transluminal Laser Angioplasty : From the \\ Experimental Model in Live Dogs to Clinical \\ Experience in Peripheral Arteries \\ 吉畞正人、阔田!義、过義颜、中村和夫 \\ Masato Yoshida、Masayoshi Okada、Yoshihiko Tsuji、 \\ Kazuo Nakamura

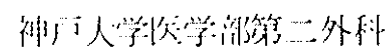

Experimental studies were carried out to evaluate the safety and efficacy of argon laser recanalization using the bare ended probe (BEP) and the metal tip probe (MTP) in canine femoral arteries with thrombus formation.

The results of angiography indicated that widening of luminal occlusion with thrombus was seen in only 3 of 12 dogs treated with BEP compared to 11 of 12 dogs treated with MTP. Perforation of the arterial wall occurred in 9 of 12 dogs using BEP and in only 1 of 12 dogs treated with MTP. Histologic examination demonstrated that the newly created channels made with either BEP or MTP were circular in shape and accompanied by charring in its surface. The intraluminal surface with MTP was smoother than with BEP. The larger MTP was available to create a wider channel. We employed also angioscope to observe the obstructive changes of the vessels and to vaporize the thrombus safely using BEP. Angioscope was inevitable to make a diagnosis and to keep safety for laser angioplasty.

On the basis of these experimental studies, percutaneous transluminal laser angioplasty was successfully employed 11 patients with severe intermittent claudication and rest pain or ulcer on legs. Two occlusive lesions and 9 stenoses were successfully dilated by this procedure. In 7 cases additional dilatation was carried out with balloon catheter. No significant complications of perforation, dissection, spasm of the arteries, or embolism were observed. Especially in clinical case, the utilizations of angioscope and guide wire were effective to keep the safety of laser angioplasty. 
レーザーの殹学への応用は近年、条领域で研究 が進められている。しかし、心臟血管外科领域に おけるレーザーの応用はいまだ確立されておら ず、種々の問題が残されている。今[门]、我々は、 Argon レーザーを用いたLaser angioplasty の 実験的研究ならびに臨林応用を行い、その有用件: を検㣙したので報告する。

\section{(A) '赛験的研究}

\section{I. 研究対象と方法}

Argon laser delivery system $と し て L a s e r$ Ionics社製 Model 556Aを用いた。をたLaser probeとしては直径0.7mmのare ended probe (以下BEP) と直径 $1.5 \sim 2.5 \mathrm{~mm}$ の Metal tip probe (以下MTP)の2種類を用いた。BEPで は先端からでるlaser beamによって直接、侾変 部が烝散されるがMT Pでは先端の金属部でレー ザーエネルギーを熱エネルギーに変換して病変激 を燒灲する方法である。

1）動脈壁に対する反応

ヒト屍体より得た大動脈に、等気、血液、生食 水の3つの条件下でレーザー照射を行い血管臂に 対する組織反応を検討した。

2) Transluminal laser angioplasty $の$ 䒠施 有法

犬大腿動脈にFogarty balloon catheterを插 入して内膜を損㑺させた後、トロンビン加目家血 を注入する方法で、2から6週間後に血管肉腔が 器質化血栓によって閉塞する事実を血管造影なら びに組織学的検剖で確認したこ。の血栓モデルを 12頭の犬に作成して、実際に生体で translu minal laser angioplastyを施行し検副を加之 た。またこの際、血管内視鏡の僧用を行ってお。 り、内視鏡のchannel 内にlaser probe を挿入す ることによって病変部を直視下に観察しながら、 血栓部をレーザー照射した。

II. 研究成績並びに考察

1）動脈壁に対する反応

穿孔が発生するエネルギー量および血管壁の組 織反応からみてBEPでは2〜3 J、MTPでは 約 $20 \mathrm{~J}(6 \mathrm{~W} 、 3$ 秒)が 1 回照射の安全かつ有効な

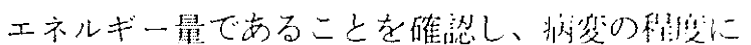
伈じて交後照射するのが得策と考方的机た。また 一方、レーザー照射を行う mediumによってその

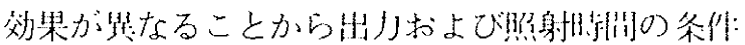
は適宜叮変する必仼があっだ。

2) Transluminal laser angioplasty $の$ 成縚! 犬血枪モデルにおける1[照射の条俳はヒ卜夗

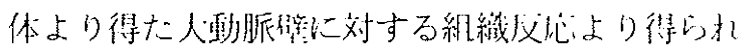
た結果にもとづ、てBEPでは2W、1 秒、MT $\mathrm{P}$ では6W、3秒としrecanalizationが得られる まで澓照射を行った。

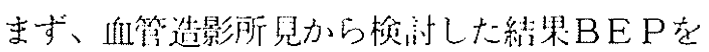
使用した場令には12例中，3例(25\%) Trecanalizationが得られたが、残りの9例ではレーザーの

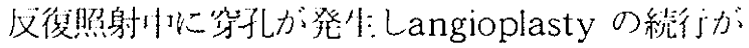
不问能となった。こ机に対してMTPでは12例中

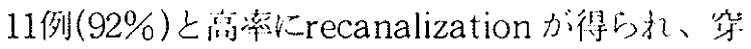
孔はわずか 1 例に溜めたの文であり、後者でより 安食にangioplasty が主施された(永1。)。また BEPでの第孔例を検测したところ、いずれも佔 管壁に接触した状態でレーザー照射を続けた場介 に発生した。この事莍よりBEPを使朋する場命

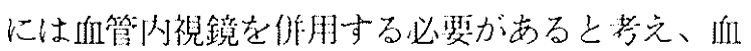
枪閉寒部を直視下に観察しながらレーザー照射を 行ったところ第孔を起こすことなく安食にrecan alization することができ、一问照射のレーザー エネルギー量も增加させることができた。した がって、BEP使用下でも血管内視鏡の㭛用例で は穿孔例はなく良好な結果を得ている。

次にrecanalization が得られた排洌の血管造影 所見をBEPとMTPで比䡆したところ、BEP では開通したchannel は小さく造影も佷良であり 不十分な血流しか得られなかった。これに対 LM TPではTip の大きさに応じたchannelが形成さ れ十分な血流改善が得られ B E P と対比してょり 有效であった。しかし、砸化性病变に対してBE PはMT P と対比してょり有効であり、血管病変 の所見に応じてBEPとMTPを作用するのが有 用であると考えられた。

血管内腔の観察には、我々が試作した血管內視 


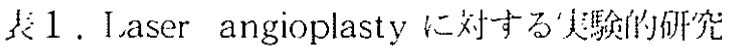

\begin{tabular}{|c|c|c|c|c|c|c|c|c|c|}
\hline \multirow{2}{*}{ 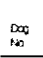 } & \multirow{2}{*}{$\begin{array}{l}\text { rnombis } \\
\text { soe (neet) }\end{array}$} & \multicolumn{2}{|c|}{ 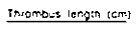 } & \multicolumn{4}{|c|}{ 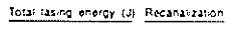 } & \multirow{2}{*}{\multicolumn{2}{|c|}{ 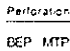 }} \\
\hline & & BEP & $\therefore M P$ & BEP & MTP & $B E P$ & i.mp & & \\
\hline 1 & 2 & 3.0 & 3.5 & 24 & 108 & + & + & - & - \\
\hline 2 & 2 & 3.0 & 4.0 & 6.4 & 1.4 .4 & + & + & - & 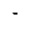 \\
\hline 3 & 2 & 40 & 45 & 28 & 126 & + & + & - & - \\
\hline t & 2 & 3.0 & 45 & 36 & $\$ 14$ & - & + & + & - \\
\hline 5 & 2 & .1 .0 & 3.0 & 60 & 252 & - & + & + & - \\
\hline 6 & 3 & 5.0 & 3.0 & 28 & 216 & - & + & + & - \\
\hline 7 & 3 & 6.5 & 4.0 & 20 & 198 & - & + & + & - \\
\hline s & 4 & 6.0 & 5.0 & 16 & 324 & - & + & + & - \\
\hline$s$ & 4 & 7.0 & 6.0 & 32 & 396 & . & + & + & - \\
\hline 10 & 4 & 5.0 & 5.0 & 45 & 450 & - & + & + & \\
\hline 11 & 4 & 4.5 & 40 & 52 & 360 & - & + & + & - \\
\hline 12 & 6 & 3.0 & 6.0 & 5.4 & 450 & - & - & + & + \\
\hline \multicolumn{2}{|c|}{$\begin{array}{l}\text { Total or } \\
\text { mean=sD }\end{array}$} & $\begin{array}{r}4.50 \\
-1.43\end{array}$ & $\begin{array}{l}1.38 \\
: 1.0\end{array}$ & $\begin{array}{r}38.3 \\
=16.2\end{array}$ & $\begin{array}{r}287 \\
: 128\end{array}$ & 3 & 11 & 9 & 1 \\
\hline
\end{tabular}

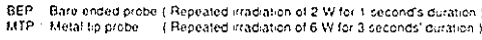

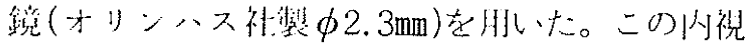

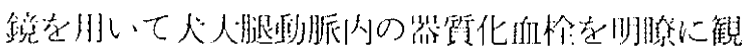

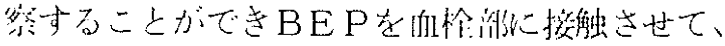
レーザー紧射を行うことも叮能で范った。立た、 レーザー照的によって形成されたchannel 袁観察 したところ、BE Pではスホット状の小さな channel として観察さ扎たが、MTPではTipの

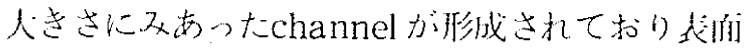

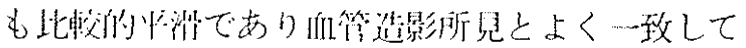
いた。なお、レーザー照射された机筧队膜涌には

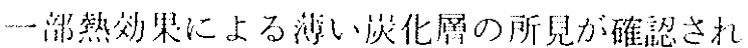

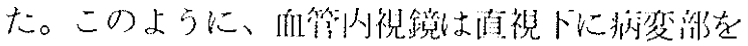
観繁することができ、laser angioplasty の実

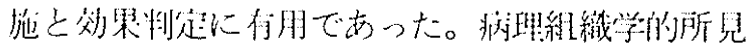
を観察したところ、レーザー照射によって形成さ れたchannelはBEP、MTPともほぼ形を星

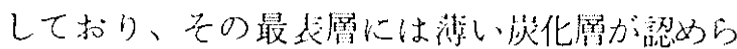
れ、その直下には熱による細胞の变州:像が確認さ れたが、MTPではBEPと比䡈してその表面は より燿であった。

(B) 臨狇灾拥

基礎的研究でBEPおよびMTP使用下での安 全かつ有效な照射条件之手技を確立した後、臨林 例に応用した。現在までに下肢閉舆性:動脈硬化将: およびBuerger 病の11例に対してlaser angio plastyを行った。

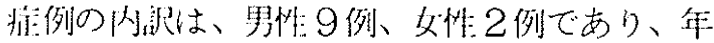

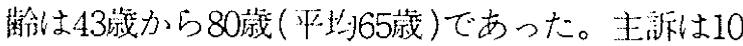
例が間矢吽跛行、1 例が、安静時疼痛および難治件 渱瘍であった。病变济位は腸骨動脈領域 5 例、大 腿動脈領域 5 例、人工血管閉塞１例であった。血
立2. Laser angioplasty の㹂从沈用 (レーザー热射解の所見)

\begin{tabular}{|c|c|c|c|c|c|c|}
\hline \multirow{2}{*}{$\begin{array}{l}\text { Cass } \\
\text { so. }\end{array}$} & \multirow[t]{2}{*}{18.0} & \multirow[t]{2}{*}{$\sin x$} & \multicolumn{3}{|c|}{ L.ession } & \multirow[t]{2}{*}{ Sraplesa } \\
\hline & & & artesy & stenusis(a) & $1 \operatorname{sen} 8 \operatorname{th}(\mathrm{cs})$ & \\
\hline 1 & 62 & .4 & $\mathrm{cis}$ & 20 & 1.5 & claudicalion \\
\hline 2 & 62 & . & $\mathrm{Cr}$ & 90 & 2.0 & ciauticatiun \\
\hline 3 & 69 & M & SFA & 100 & b. 0 & rest painuluer \\
\hline 4 & 43 & 1: & firalt & 90 & 1.0 & claudication \\
\hline j & 61 & M & in & 100 & 1.0 & claudicalion \\
\hline 6 & 80 & y & SHA & 90 & 1.0 & claudication \\
\hline 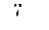 & B) & in & Bit & 75 & 1.5 & claudicaliun \\
\hline 8 & 66 & M & $B: 1$ & 90 & 1.0 & claudication \\
\hline 9 & 72 & M & SFA & 90 & 2.0 & claulicaliesn \\
\hline 10 & $\therefore i$ & $1:$ & cit & 90 & 9.0 & clatitication \\
\hline$! 1$ & 70 & $w$ & 181 & 90 & 1.5 & clidulfcation \\
\hline
\end{tabular}

衣3. Laser angioplasty 臨休例の成繶

\begin{tabular}{|c|c|c|c|c|c|c|c|c|}
\hline Case & lasuer & energy(3) & Pil & Sten & sis( $(9)$ & P'resserure & Index & Symption \\
\hline$s_{0}$ & $B F P$ & צTP & & I're. & Post. & Pre.: & fios:. & \\
\hline 1 & 216 & & $(\cdot)$ & 90 & 25 & 0.63 & 1.20 & inproved \\
\hline 2 & 216 & 1200 & (1) & 90 & 0 & 0.61 & 0.91 & inproved \\
\hline 3 & & 2000 & (.) & 100 & 0 & 0.11 & 0.19 & imprevesd \\
\hline 4 & & 180 & $($ ) & 90 & 0 & & & improved \\
\hline i) & & 360 & (i) & 100 & 0 & 0.13 & 0.86 & inproved \\
\hline 6) & 20 & 340 & $6 !$ & 90 & 25 & 0.53 & 1.00 & inptovest \\
\hline ; & & 1600 & (.) & 75 & .30 & 0.60 & 0.92 & improvered \\
\hline 8 & & 360 & $(1)$ & 90 & so & 0.59 & 0.61 & improves: \\
\hline 9 & 2.52 & 100 & (.) & 90 & 0 & 0.52 & 0.53 & inproved \\
\hline 10 & & 1360 & ( ) & 90 & 2.3 & 0.12 & 0.82 & insored \\
\hline $1 !$ & & .570 & $(1)$ & 90 & 20 & 0.57 & 1.13 & implove:d \\
\hline
\end{tabular}

管造影では、いずれも75\%以上の高度狭窄怔例で あり完全閉寒为洌が 2 例含ま机ていた。病变部の 長さは $1 \mathrm{~cm}$ から $9 \mathrm{~cm}$ (汹 $2.8 \mathrm{~cm}$ )であった（表 2.)。Laser angioplasty の実施力法は全例、 局所麻酸下にて行ったが、穿制法により大煺的脈 に8.5から 9Fr のsheath catheterを挿入、留濯 した後に、まず血管内視鏡にて病変部の状態を十 分に観察する。次にBE Pを使用する場合には穿 孔を未然に防ぐために血管内視鏡を作用して病変 激を直視下に観察しながらレーザー照射を行っ た。途中でMTPに变更して使用する場合は、原 則として透視下に適時造影をしながらレーザー照 射を行っているがこの際最も留意すべき点は guide wire の㑊用である。我々は0.035inch の guide wire の通る側孔のある直径 $2.5 \mathrm{~mm} の \mathrm{MT}$ Pを使用しており、guide wire 誘導下にLaser probeを進めるようにしており、この手技によっ て血管壁の穿孔、内膜解離などの合倒症力防止で きると考えている。照射条件としてはBEPおよ びMTPともに $6 \mathrm{~W} 、 3$ 秒を一単位として反復照 射を行った。また、MTP使用の場合には、効果 がイ゚十分な症例には適時一回照射のワット数、秒 


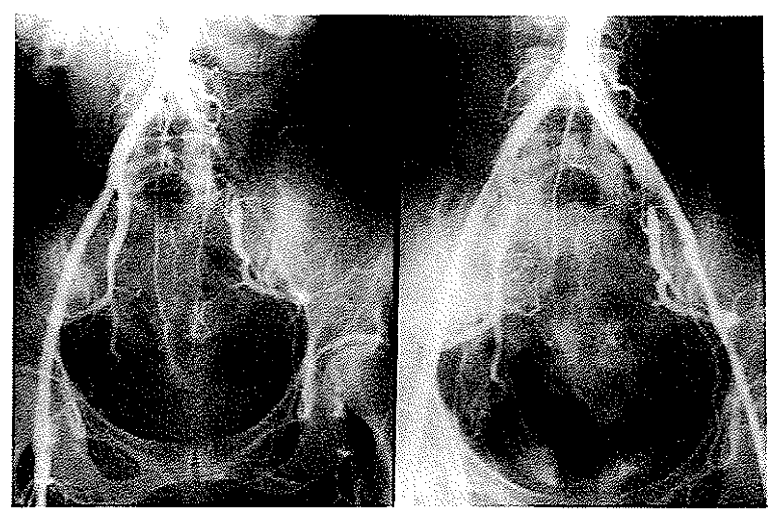

図 1。MTPによるLaser angioplasty の臨林 左：レーザー照射前、右：レーザー照射後

数を增加させた。

その結果、総エネルギー量は変化したが全例、 血管造影にて狭密部の改盖拈よび閉寒湖の開通が 得られた。この際、 laser angioplasty にて效果 の什十分な 7 例ではballoon catheterによる $\mathrm{P}$ TAを追加した。またレーザー照射中、全我洌に おいて穿孔および末梢寒枪㳥などの合作为注核め られなかっだ。Pressure indexに関しては11例 中8例で著しい改善が得られたが残り3例では変 化がなくこのらち2例は未梢のrun off が住良

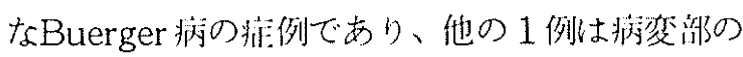
硬化㧍よび動脈の屈曲、蛇行が漒くangioplasty が不十分に終わった班例であった。ところが、臨

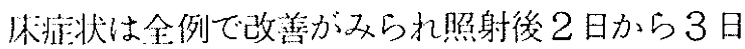
という短期間で退院した2゙ー5（表3。）。

次に、血管造影所見および血管内内視鏡所見を代 表的な症例で呈示する。症例10の術前血管造影所 見では、左総晹路動脈から外腸骨動脈にかけて長 さ約 $9 \mathrm{~cm}$ たたる広範な狭窟病変を認めたか $\mathrm{MT}$ Pを使用してレーザー照射を行い、狭窄は十分に 改善され良好な血流を得ることができた。この狱: 例ではLaser angioplasty だけで予想以上に噼 好な血流改善を得ることができ balloon cathe terによるPTAは追加されなかった(図 1.)。济: 例2の血管内視鏡所見では、右大腿動脈にスリッ ト状に狭小化した内腔が認められ、造影所見では 90\%の狭窄病変を呈しており、BEPによるレー ザー照射により狭窄部は開大したが、BEPに よって蒸散される䡝用は少なく、本症例では内視 鏡を回転させたり、体外より用手的に压迫するこ

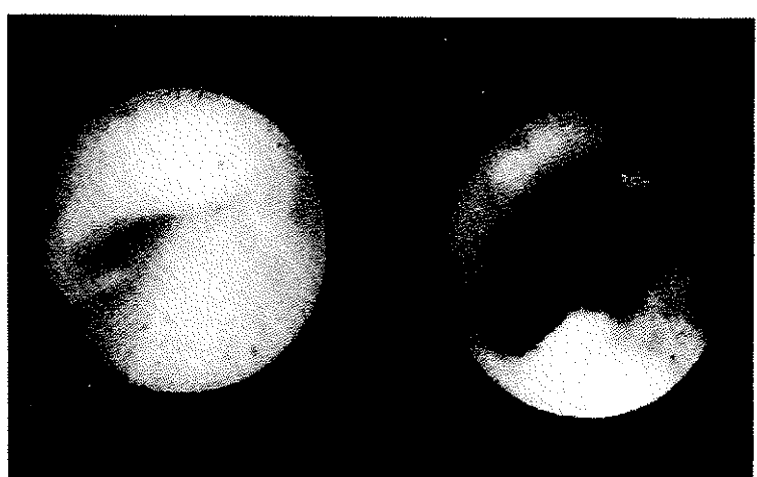

図2，血管内視鏡下に批るLaser angioplasty 左：レーザー照射前、右：レーザ一典射後

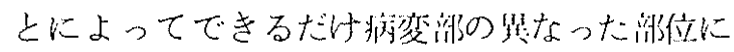
laser probe を当てるように内腔の開人をは かった。しかし、その効果にも限界が欢られ、結 局、MTPによるレーザー照射およびPT Aが追 加された（図2．）。このような所兄より、BEP 使用の際にはbending機構老有する血管们視鏡の 改良の必要吽があるものと感じられた。

結活

1) Argon laserを用いた laser angiopla -

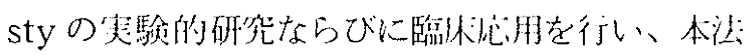
の有用非:を確㴓した。

2) BEPとMTPを対此したところ、とくに 後者で安全でかつ十分な血流改摔が得ら机た。东 た、そ机ぞれのLaser probeの特亚をを生かし、 血管病変の所見に心じて邽者を作用するのが得策 であると考光られた。

3）血管内視鏡はLaser angioplasty の安食 な実施と效果の判定に有用であったが、bending 機構などの改良の余地があると考えられた。 文献

1) 过義諺：日本レーザー医学会贸 8 ： 153, 1987.

2) 阔田昌義:日本レーザー医学全誌 $8: 5$, 1987.

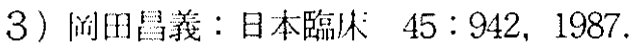

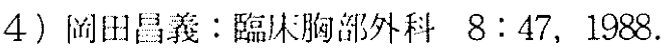

5 ) Okada $\mathrm{M}$. et al : Surgical and $\mathrm{Me}^{-}$ dical Lasers 1:53, 1988. 